\title{
O EFEITO DA INSTRUÇÃO EXPLÍCITA DE SÂNDIS EXTERNOS DO INGLÊS NO DESENVOLVIMENTO DA PERCEPÇÃO AUDITIVA DE APRENDIZES BRASILEIROS
}

\section{THE EFFECT OF THE EXPLICIT \\ TEACHING OF EXTERNAL SANDHIS IN THE DEVELOPMENT OF THE LISTENIG ABILITIES OF BRAZILIAN LEARNERS OF ENGLISH}

\author{
Ronaldo Mangueira Lima Júnior ${ }^{1}$ \\ Universidade Federal do Ceará (UFC) \\ Thiago Ribeiro Mendes ${ }^{2}$ \\ Universidade Federal do Ceará (UFC)
}

\section{RESUMO}

Esta pesquisa teve por objetivo analisar o efeito do ensino explícito de sândis externos do inglês para aprendizes brasileiros de inglês como língua estrangeira no desenvolvimento da percepção auditiva. O estudo toma como perspectiva o ensino de sândis à luz do Ensino Explícito e das Teorias de Percepção (ALVES, 2004; BYBEE, 2001; ELLIS, 2008; JOHNSON, 1997). Foi realizada uma pesquisa com aprendizes de nível iniciante e intermediário, subdivididos em grupos controle e experimental. Todos os alunos passaram por um pré-teste de compreensão auditiva; os alunos dos grupos experimentais tiveram instrução explícita sobre sândis externos em inglês; e todos os alunos foram novamente testados em compreensão auditiva. Os resultados apontam que o ensino explícito de sândis permitiu aos alunos uma melhor percepção auditiva.

PALAVRAS-CHAVE: Instrução Explícita; Percepção Auditiva; Sândis

\begin{abstract}
The aim of this paper is to analyze the effect of explicit teaching of external sandhis in English for Brazilian students of English as a foreign language. This study follows the perspective of teaching sandhis according to Explicit Instruction as well as of Perception Theories (ALVES, 2004; BYBEE, 2001; N. ELLIS, 2008; JOHNSON, 2004). The study was conducted with Brazilian learners of English, both beginners and intermediate, who were further divided into control and research groups All learners were pre-tested in their listening abilities; the ones from the research groups received explicit instruction on external sandhis of English; and all learners were again tested on their listening abilities. The results show us that the explicit teaching of sandhis allowed students to have better listening performance.
\end{abstract}

KEYWORDS: Explicit Instruction; Auditory Perception; Sandhis

\section{INTRODUÇÃO}

Pesquisas na área da Fonética e Fonologia têm feito relevantes contribuições para o campo da Linguística Aplicada e, por sua vez, para o ensino de línguas estrangeiras (FRASER, 2001; GILBERT, 2008; PENINGTON, 1996). Entre elas, há as que buscam investigar os efeitos do ensino explícito de pronúncia e/ou do treinamento perceptual no processo de aquisição do inglês-L2 (e.g. ALVES, 2004; N. ELLIS, 2008; LIMA JR, 2010; PEROZZO, 2013; SCHMIDT,

\footnotetext{
${ }^{1}$ Doutor em Linguística (UnB), professor da Universidade Federal do Ceará. E-mail: ronaldojr@letras.ufc.br 2 Mestre em Linguística (UFC), professor da Secretaria da Educação do Estado do Ceará (SEDUC). E-mail: thiagoribeiromendes@yahoo.com.br.
} 
1990; SILVEIRA; ALVES, 2009). Esta pesquisa procura contribuir para esse vasto campo ao investigar o desenvolvimento da aprendizagem perceptual dos aprendizes de inglês-L2 mediante instrução explícita de sândis externos.

Muitos são os estudos a respeito do ensino de pronúncia das línguas estrangeiras no contexto das pesquisas linguísticas na área aplicada. Observa-se que grande parte desses estudos se concentra em investigar sons isolados ou indo até o âmbito da pronúncia da palavra (FLEGE, 2003). Perucci (2005) aponta a simplificação do ensino de aspectos linguísticos isolados de pronúncia como forma de facilitar as tarefas de compreensão auditiva nos materiais didáticos que têm princípios do método comunicativo. Contudo, pouco se fala a respeito do ensino de sândis e a respeito de sua percepção auditiva dos mesmos.

Os sândis são aspectos do fluxo natural da fala (CELCE-MURCIA, 1996) e, dessa forma, pesquisas envolvendo tais aspectos linguísticos são imprescindíveis, principalmente no campo do ensino das línguas adicionais. Poucos materiais de ensino de línguas focam na instrução de aspectos de pronúncia na fronteira entre palavras, os sândis externos, e, muito menos, na aprendizagem perceptual dos alunos. Entretanto, os fenômenos fonéticos que podem acontecer nas fronteiras de palavras são fonte de dificuldade na percepção de alunos, que muitas vezes relatam que os falantes nativos de inglês falam rápido demais, ou não falam como os alunos aprenderam. Tomemos, por exemplo, uma sentença como "night and day". Ela provavelmente será pronunciada com todos os sons presentes em transcrições de dicionários, [naIt ənd deI], que é a expectativa da maioria dos aprendizes, apenas se dita intencionalmente pausadamente. Em uma situação natural de fala encadeada, ela provavelmente soará mais próxima de [naIrnder], com as supressões de sons vocálicos e consonantais e ligações entre os vocábulos típicas desse sândi externo, dando a sensação ao aluno de que a frase foi dita muito rápida.

Sendo assim, este presente estudo teve por objetivo investigar o efeito que a instrução explícita dos sândis externos poderia ter sobre aprendizes de inglês como língua estrangeira no que diz respeito à percepção auditiva. Nossa pesquisa tem como norte a pergunta: qual é a influência do ensino explícito de fenômenos de sândis externos da língua inglesa ao ser usado como um instrumento na aprendizagem perceptual da língua falada com aprendizes brasileiros?

Levamos em consideração como hipótese básica que o ensino explícito de aspectos suprassegmentais como os de elisão e de liaison, dentro da sala de aula de inglês-L2 promove uma melhor percepção auditiva de alunos de inglês como língua estrangeira. Por instrução explícita nos referimos a uma seleção de regras ensinadas com o intuito de encorajar uma consciência metalinguística e prática da regra. Essa consciência pode ser atingida de forma dedutiva, quando o aprendiz é levado a compreender o fenômeno por meio da regra; ou indutiva, quando o aprendiz é auxiliado a descobrir a regra por si próprio a partir de dados providos com o fenômeno em foco (DEKEYSER 1995; R. ELLIS 2008).

Isso implica que concordamos com a premissa de que conhecimento explícito/declarativo por se transformar em conhecimento implícito/processual, isto é, que ter instrução metalinguística em língua estrangeira, contanto que seguida de prática significativa e comunicativa da língua, pode contribuir com o desenvolvimento linguístico como um todo (ALVES, 2004; DEKEYSER, 1995; R. ELLIS, 2001; LIMA JR, 2010). Tomamos por pressuposto também que bilíngues não usam dois subsistemas fonéticos, língua um e língua dois, separadamente, mas sim um único sistema que interage (FLEGE 1995; LEATHER, 2003), e que, por isso, sua percepção de uma língua estrangeira será influenciada pelos padrões já bem estabelecidos para a sua língua materna (FLEGE, 2003; PEROZZO, 2013).

\section{Método}

Participaram do estudo quatro grupos de aprendizes provenientes de um curso de inglês que faz parte de um projeto de extensão ofertado ao público em geral na Universidade Federal do 
Ceará. Os cursos ofertados têm uma duração de sete semestres, com uma carga horária de 420 horas, e são ministrados em língua inglesa por professores concursados. Foram selecionadas duas turmas de nível básico (segundo semestre - SII) e duas de nível intermediário (sétimo semestre SVII) para participarem da pesquisa. Uma turma de cada nível foi utilizada como grupo controle, participando apenas das fases de pré- e pós-testes, no início e no fim de um semestre letivo, respectivamente. Semelhantemente, uma turma de cada nível foi utilizada como grupo experimental, passando pelos pré- e pós-testes, mas também por quatro sessões de 20 minutos de instrução explícita sobre sândis externos entre os testes, o que também tomou apenas um semestre letivo. Ao todo participaram 40 alunos, sendo 9 em cada turma controle, 12 na turma experimental de segundo semestre, e 10 na turma experimental de sétimo semestre. A idade média foi de 22 anos, todos os participantes eram brasileiros, e nenhum afirmou ter morado fora do Brasil. Quanto à escolaridade, nove participantes estavam cursando a graduação, e os demais tinham nível superior completo.

A fim de coletar os dados, contamos com a colaboração dos professores regentes das turmas, que cederam os 20 minutos finais de duas aulas nas turmas controle, para condução dos pré- e pós-testes; e os 20 minutos finais de seis aulas nas turmas experimentais, uma para o préteste, quatro para as intervenções com instrução explícita (conduzidas pelo pesquisador principal), e mais uma para o pós-teste.

Para elaboração do teste, que serviria tanto como pré- e pós-teste, começamos listando palavras e pequenas frases que poderiam favorecer fenômenos de sândis de diferentes tipos e de alta frequência no inglês, conforme descrito na literatura (e.g. CELCE-MURCIA ET AL, 1996; BISOL, 2000; PERUCCI, 2005). Em seguida, pesquisamos no COCA (Corpus of Contemporary American English) sentenças em que essas palavras apareciam, chegando à lista de 70 sentenças. Pedimos a um falante nativo de inglês americano que gravasse as sentenças, sem nenhum tipo de instrução sobre como ele deveria pronunciar as sentenças, apenas solicitando que as gravasse da forma mais natural possível. A seguir, selecionamos aquelas em que os sândis apareceram, procurando mesclar os tipos. O resultado foi a lista de 26 frases a seguir, em que o trecho com sândi externo está destacado e com a transcrição fonética aproximada de como ficou a gravação do trecho.

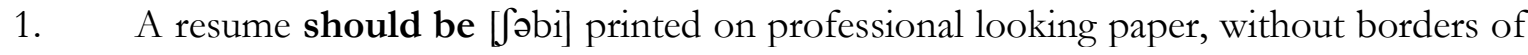
school buses or apples.

2. I go to private class [praIvəklæs].

3. I felt like [felark] my house was being broken into.

4. Have you ever tried kissing [traIkIsIy] someone?

5. What did that [dıðæt] mean to her?

6. It could be [kubi] a commercial.

7. Dusty's going to [gənə] blow this place up.

8. Let him [lerim] go

9. He was out of [aorə] sugar.

10. They react to [riæktə] that capability.

11. There's so many things that don't add up [ærıp] anything.

12. He's not going to [gənə] leave you.

13. I'm crazy about it [obaurit].

14. Ask him [æskIm].

15. I went to [went?] the Methodist church.

16. She'll work part time [partaIm] for a home-care agency.

17. There's a lot of [larəv] energy in playing music.

18. Do you want to [wano] tell me what you are thinking? 
19. The two were determined to be eight to [eItu] 10 feet apart when the final shot was fired.

20. All the things he says every day [EvrideI] in his small mystic moments.

21. You become what you [warju] think.

22. I do believe in evolution [inevolu $\int \mathrm{n}$ ].

23. As far as [faræz] I can tell the public transport system is fine.

24. I'm a [aimə] big skiier.

25. I've got to [garə] go, Lanna.

26. Anything else you want to [wanə] avoid telling me?

Os fenômenos de sândis aqui apresentados foram escolhidos por serem comuns na língua inglesa e por trazerem dificuldade de percepção aos aprendizes de inglês-L2. São fenômenos que deixam a sensação de que a frase foi falada "rápido demais", sendo que, na verdade, não há alteração na taxa de elocução, há apenas fenômenos de inserção, elisão, redução e assimilação. Além disso, não são comumente ensinados em materiais didáticos usados em sala de aula.

Para a aplicação dos pré- e pós-testes, nas quatro turmas, os alunos foram instruídos que escutariam sentenças em inglês, que cada uma seria tocada duas vezes, e que haveria um intervalo de tempo entre cada frase para que escrevessem suas repostas na ficha. As frases foram as mesmas para as quatro turmas, porém, a fim de permitir a consecução da tarefa pelas turmas de nível básico (semestre II), para essas a tarefa foi de preenchimento de lacunas, na qual os trechos em que houve sândi (destacados na lista de frases acima) foram os lacunados. Para as turmas de nível intermediário (semestre VII), os alunos foram instruídos a transcrever por completo cada uma das 26 frases. O mesmo teste foi utilizado como pré- e pós-teste e não houve frases distratoras.

As intervenções feitas com os aprendizes dos grupos experimentais de segundo e sétimo semestres (SII e SVII) tiveram mais ou menos a mesma configuração. Foram 4 encontros em cada turma, nos quais o pesquisador se utilizou dos últimos 20 minutos de cada aula. $\mathrm{Na}$ condução dessas intervenções, o pesquisador utilizou cartazes com as regras escritas de cada fenômeno de sândi: tipo, em que contexto fonológico ele pode aparecer, exemplos, e, sempre que possível, tocava um áudio em que esse fenômeno acontecia. Após cada período de ensino explícito, o professor conduzia um período de repetição com os aprendizes para que fixassem o que havia sido aprendido em cada intervenção. Em cada intervenção foram discutidos alguns fenômenos de sândis, conforme apresentado a seguir:

\section{- Intervenção 1:}

- Contração das locuções want to (wanna), going to (gonna), got to (gotta)

- Elisão de /t/ e /d/:

- Ex.: last night, old car, private class, should be, went to, tried kissing

$\circ / \mathrm{t} / \mathrm{e} / \mathrm{d} /$ pronunciado como [r] em posição intervocálica

- Ex.: a lot of, add up, about it, what you

\section{- Intervenção 2:}

- Elisão de /h/ no início dos pronomes he, his, her, him

- Ex.: I thought he was, ask bim

- Elisão de /h/ nos verbos auxiliares have, has, had

- Ex.: The students bave all left.

\section{- Intervenção 3:}

○ Elisão de / $/$ na palavra of

- Ex.: out of sugar

- Ligação e assimilação em frases como in evolution, every day in

\section{- Intervenção 4:}


○ revisão e prática

\section{Resultados e discussão}

Nas tabelas a seguir, apresentamos o número de acertos de cada participante bem como suas notas em uma escala de 0 a 10 , lembrando que cada teste tinha um total de 26 itens. Na tabela 1 apresentamos os dados do grupo experimental (PE) de alunos do segundo semestre (S II).

\begin{tabular}{lcccc}
\hline Participante & $\begin{array}{c}\mathbf{N}^{\mathbf{o}} \text { acertos no } \\
\text { Pré-teste }\end{array}$ & Nota & $\begin{array}{c}\mathbf{N}^{\mathbf{o}} \text { acertos no } \\
\text { Pós-teste }\end{array}$ & Nota \\
\hline S II PE 1 & 15 & 5,77 & 20 & 7,69 \\
S II PE 2 & 4 & 1,54 & 6 & 2,31 \\
S II PE 3 & 3 & 1,15 & 11 & 4,23 \\
S II PE 4 & 5 & 1,92 & 20 & 7,69 \\
S II PE 5 & 10 & 3,85 & 19 & 7,31 \\
S II PE 6 & 14 & 5,38 & 12 & 4,62 \\
S II PE 7 & 5 & 1,92 & 12 & 4,62 \\
S II PE 8 & 3 & 3,85 & 5 & 1,15 \\
S II PE 9 & 2 & 0,77 & 7 & 2,69 \\
\hline Média & 6,78 & 2,91 & 12,44 & 4,7 \\
\hline
\end{tabular}

Tabela 1 - Análise por participante SII - Grupo experimental

Fonte: dados da pesquisa

Primeiramente, podemos observar que no pré-teste há uma diferença de acertos grande entre os participantes do grupo analisado. Temos o participante SII PE 1, que teve um acerto de 15 itens, enquanto outro participante do mesmo grupo, SII PE 9, acertou apenas 2 itens. Mais uma vez, é importante ressaltar que cada aluno tem uma formação diferente; de fato, não esperávamos encontrar homogeneidade nos grupos, mas tampouco uma diferença tão grande, o que demonstra a necessidade desses assuntos serem abordados nas aulas. Houve bastante evolução, mesmo com tão poucas intervenções. Tivemos casos de participantes que deram um salto de percepção dos fenômenos de sândis após o período de instrução. Um exemplo é o participante SII PE 4, que no período da pré-testagem percebeu de forma correta apenas cinco sândis, obtendo nota de 1,92. A análise de suas respostas revela que ele demonstrava dificuldades na percepção, por exemplo, de elisão de /d/, elisão de /h/ e palavras como gonna e wanna. Após o período das intervenções, o mesmo participante deu um salto para percepção de 20 itens, em que fenômenos de pronúncia foram mais bem percebidos pelo participante. Todos os aprendizes do grupo experimental demonstraram uma melhora no número de acertos. A média de acertos da turma no pré-teste foi de 6,78i tens, enquanto que após o período das intervenções o número aumentou para 12. Um teste de Wilcoxon pareado retornou um valor de $\mathrm{p}$ significativo $(\mathrm{W}=2, \mathrm{p}=0,01)$, o que confirma que houve uma melhora considerável entre os dois momentos que a turma vivenciou, confirmando como satisfatórios os resultados proporcionados pelas intervenções.

Em conversa com o professor titular das turmas, fora da sala de aula, o mesmo afirmou que os alunos vez por outra chamavam a atenção para a pronúncia de certa palavra dentro do contexto que poderia acontecer o sândi, e, dessa forma, pronunciavam com o sândi correspondente. Certamente a instrução ensinada nos momentos das intervenções os auxiliaram a não somente perceber, mas também a se auto monitorarem na pronúncia de palavras e possíveis sândis.

O quadro a seguir apresenta os dados da turma controle do semestre II, que recebeu apenas as aulas regulares com o professor titular, e não teve intervenções com instrução explícita de sândis. 


\begin{tabular}{lcccc}
\hline Participante & $\begin{array}{c}\mathbf{N}^{\mathbf{o}} \text { acertos no } \\
\text { Pré-teste }\end{array}$ & Nota & $\begin{array}{c}\mathbf{N}^{\mathbf{o}} \text { acertos no } \\
\text { Pós-teste }\end{array}$ & Nota \\
\hline S II PC 1 & 3 & 1,15 & 3 & 1,15 \\
S II PC 2 & 4 & 1,54 & 3 & 1,15 \\
S II PC 3 & 4 & 1,54 & 4 & 1,54 \\
S II PC 4 & 6 & 2,31 & 8 & 3,08 \\
S II PC 5 & 2 & 0,77 & 2 & 0,77 \\
S II PC 6 & 9 & 3,46 & 9 & 3,46 \\
S II PC 7 & 5 & 1,92 & 9 & 3,46 \\
S II PC 8 & 9 & 3,46 & 13 & 5,00 \\
S II PC 9 & 4 & 1,54 & 5 & 1,92 \\
S II PC 10 & 6 & 2,31 & 9 & 3,46 \\
S II PC 11 & 6 & 2,31 & 4 & 1,54 \\
S II PC 12 & 8 & 3,08 & 11 & 4,23 \\
\hline Média da turma & \multicolumn{5}{c}{ 5,5 } & Tabela 2- Análise por participante SII - Grupo-controle \\
\hline \multicolumn{5}{r}{ Fonte: dados da pesquisa. }
\end{tabular}

É possível observar, imediatamente, que a turma controle é mais homogênea, quando comparamos os resultados nos acertos. Os participantes que conseguiram maior número de acertos foram SII PC 6 e SII PC 8, ambos acertaram 9 itens cada um, atribuindo-se uma nota de 3,46. A nota mais baixa foi do participante SII PC 5, com apenas dois itens acertados, obtendo uma nota de 0,77 . A turma SII controle não teve nenhum tipo de intervenção ou instrução explícita sobre sândis. Foi aplicado apenas o pré-teste e o pós-teste no mesmo período. A média de acertos do grupo-controle foi de 5,5 itens no pré-teste. Após a aplicação do pós-teste nesse grupo, podemos novamente notar que o número de acertos permaneceu relativamente homogêneo, o que pode ser constatado no gráfico de caixas a seguir. Houve um leve aumento no número de acertos, com aumento da média para 6,67, afinal, os alunos continuaram tendo suas aulas de inglês e potencialmente melhorando seu desempenho global, porém esse aumento não foi significativo como o do grupo experimental. O teste de Wilcoxon pareado revelou um valor de $\mathrm{W}=5, \mathrm{p}=$ 0,08 , demonstrando que a diferença não foi estaticamente significativa.

Diferente do que aconteceu com o grupo experimental, em que todos os participantes tiveram aumento no número de respostas corretas, tivemos participantes que reduziram o número de acertos dentro do grupo controle, como é o caso do participante SII PC2, que teve nota inicial de 1,54 (4 respostas corretas), e depois obteve nota 1,15 (3 respostas corretas); e do participante SII PC 11, que no período da pré-testagem obteve nota 2,31 (6 respostas corretas) e na póstestagem caiu para uma nota de 1,54 (4 respostas corretas). A média final do grupo-controle também não teve um aumento considerável quando comparamos com o grupo experimental. A média subiu de 5,5 acertos para 6,67 (aumento de 1,17 item), enquanto no grupo experimental o aumento foi de 5,66 itens (de 6,78 para 12,44). Tal resultado atesta favoravelmente para o ensino de sândis mesmo em um nível iniciante e mesmo com poucas intervenções. O gráfico de caixas a seguir apresenta o avanço do pré- para o pós-teste no grupo controle (esquerda) e no grupo experimental (direita), mostrando visualmente que o aumento do grupo experimental foi muito mais acentuado. 


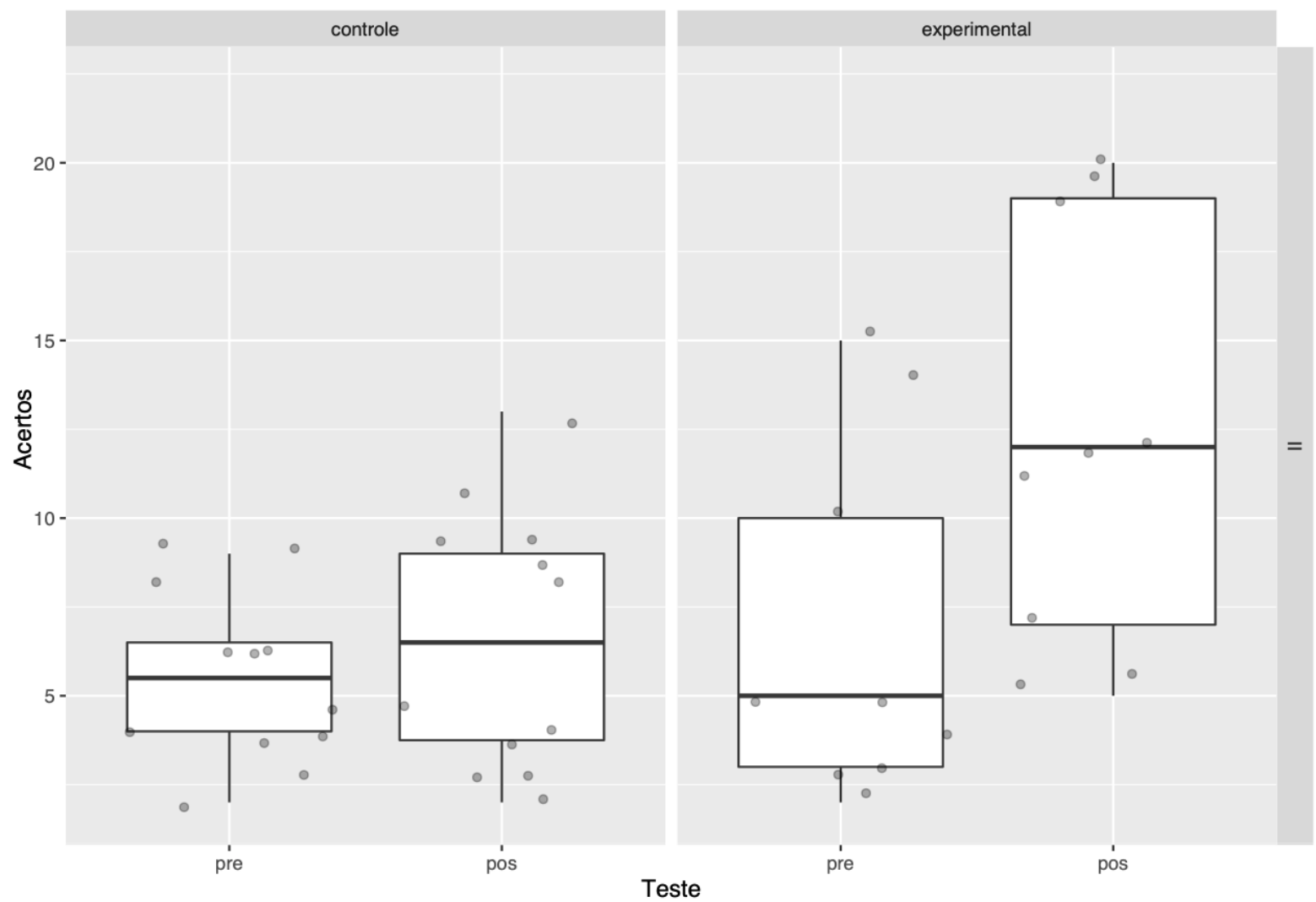

Figura 1 - Gráficos de caixa do pré- e pós-teste do grupo controle (esquerda) e grupo experimental (direita) do semestre II.

Fonte: elaborado pelos autores.

Assim como foi feito no grupo SII, as tabelas a serem analisadas a seguir, constam também dos números de acertos e das notas de 0 a 10 de cada participante do semestre VII (SVII). Novamente, começamos apresentando os dados do grupo experimental (PE).

\begin{tabular}{lcccc}
\hline \multicolumn{1}{c}{ Participante } & $\begin{array}{c}\mathbf{N}^{\mathbf{o}} \text { acertos no } \\
\text { Pré-teste }\end{array}$ & Nota & $\begin{array}{c}\mathbf{N}^{\mathbf{o}} \text { acertos no } \\
\text { Pós-teste }\end{array}$ & Nota \\
\hline S VII PE 1 & 5 & 1,92 & 9 & 3,46 \\
S VII PE 2 & 8 & 3,08 & 12 & 4,26 \\
S VII PE 3 & 3 & 1,15 & 6 & 2,31 \\
S VII PE 4 & 11 & 4,23 & 18 & 6,92 \\
S VII PE 5 & 10 & 3,85 & 16 & 6,15 \\
S V II PE 6 & 14 & 5,38 & 22 & 8,46 \\
S VII PE 7 & 8 & 3,08 & 12 & 4,26 \\
S VII PE 8 & 13 & 5,00 & 18 & 6,92 \\
S VII PE 9 & 12 & 4,62 & 13 & 5,00 \\
\hline Média da turma & 9,33 & 3,59 & 14 & 5,30 \\
\hline
\end{tabular}

Tabela 3- Análise por participante SVII - Grupo experimental

Fonte: dados da pesquisa.

Para a aplicação desse pré-teste, era necessário que os alunos escrevessem toda a sentença ouvida. Diferentemente, no grupo SII, não tinha nenhum item com questões do tipo fill in the blanks, como explicado previamente. Dessa forma, o pré-teste, bem como o pós-teste, do grupo SVII tornou-se mais desafiador. Raras foram as ocasiões em que os participantes conseguiram escrever toda a sentença correta. Com isso em mente, achamos apropriado considerar como certo o item 
em que os participantes colocassem as palavras em que os fenômenos dos sândis ocorressem, mesmo que a sentença estivesse incompleta.

No pré-teste, podemos observar o mesmo fenômeno ocorrido no grupo SII, a saber, a falta de homogeneidade no número de acertos. Isso converge com o que foi dito anteriormente, ou seja, que sabemos que os grupos apresentam pessoas com diferentes níveis de proficiência no inglês como LE. O participante SVII PE6, com o maior número de acertos (14 acertos), ficou com um nota de 5,38 enquanto que o participante SVII PE3, com o menor número de acertos (3 acertos), ficou com uma nota de 1,15. A média de acertos do grupo experimental no pré-teste foi de 9,33, que aumentou no pós-teste para 14, um avanço de 4,67. Um teste de Wilcoxon pareado revelou um valor de $\mathrm{W}=0, \mathrm{p}=0,009$, o que representa uma diferença estatisticamente significativa.

O participante SVII PE passou de 14 acertos (nota 5,38) para 22 acertos (nota 8,46), um aumento bastante acentuado. O participante SVII PE3 também passou por esse processo de melhora; sua nota passou de 1,15 (3 acertos) para 2,31 (6 acertos). Todos os outros participantes da turma mostraram melhora em seus pós-teste. Cada participante desse grupo, ao final das intervenções e prática conduzida pelo pesquisador, teve uma melhora na percepção dos sândis do tipo elisão de /d/, geminação de /t/, /t/ pronunciado como [r].

Nesse grupo não tivemos relatos do professor sobre os estudantes terem demonstrado auto monitoramento ou comentado os possíveis ambientes fonológicos em que certas palavras poderiam ser usadas com fenômenos de sândis. Porém, com os resultados encontrados, podemos confirmar que o ensino desses fenômenos em grupos avançados também é útil, ainda mais se comparados com grupos que não tiveram a mesma experiência, como pode ser constatado na comparação com o grupo-controle SVII.

\begin{tabular}{|c|c|c|c|c|}
\hline Participante & $\begin{array}{c}\mathrm{N}^{\mathbf{o}} \text { acertos no } \\
\text { Pré-teste }\end{array}$ & Nota & $\begin{array}{c}\mathbf{N}^{o} \text { acertos no } \\
\text { Pós-teste }\end{array}$ & Nota \\
\hline S VII PC 1 & 11 & 4,23 & 6 & 2,31 \\
\hline S VII PC 2 & 5 & 1,92 & 8 & 3,08 \\
\hline S VII PC 3 & 8 & 3.08 & 8 & 3,08 \\
\hline S VII PC 4 & 10 & 3,85 & 10 & 3,85 \\
\hline S VII PC 5 & 8 & 3,08 & 9 & 3,46 \\
\hline S VII PC 6 & 5 & 1,92 & 9 & 3,46 \\
\hline S VII PC 7 & 6 & 2,31 & 11 & 4,23 \\
\hline S VII PC 8 & 12 & 4,62 & 15 & 5,77 \\
\hline S VII PC 9 & 5 & 1,92 & 4 & 1,54 \\
\hline S VII PC 10 & 8 & 3,08 & 8 & 3,08 \\
\hline $\begin{array}{l}\text { Média } \\
\text { turma }\end{array}$ & 7,8 & 2,99 & 8,8 & 3,39 \\
\hline
\end{tabular}

Tabela 4 - Análise por participante SVII - Grupo-controle (continua)

Fonte: dados da pesquisa.

O grupo-controle SVII também teve pouca homogeneidade no pré-teste com relação às notas. Tivemos o participante SVII PC1, que na pré-testagem obteve nota 4,23 (11 acertos), ou, como outro exemplo, o participante SVII PC8, que obteve 4, 62 (12 acertos), notas relativamente altas em comparação com os outros aprendizes da turma, que não obtiveram o mesmo resultado, como, por exemplo, os participantes SVII PC 2, SVII PC 6 e SVII PC 9, que atingiram a mesma nota de 1,92 (5 acertos). A turma-controle SVII, assim como a turma-controle SII, não recebeu nenhum tipo de instrução sobre sândis, e sua média geral de questões certas foi de 7,8.

Diferentemente da turma experimental do SVII, o grupo controle SVII não apresentou um aumento de acertos tão acentuado. Sua média de acertos subiu de 7,8 para 8,8 , aumento de apenas 1 item, enquanto o grupo experimental teve um aumento de 4,67 itens (de 9,33 para 14). O teste 
de Wilcoxon pareado revelou um valor de $\mathrm{W}=8, \mathrm{p}=0,35$ para a diferença do grupo controle, mostrando que a diferença realmente não foi estatisticamente significativa. Os gráficos de caixa a seguir ilustram a diferença maior entre pré- e pós-teste no grupo experimental (direita).

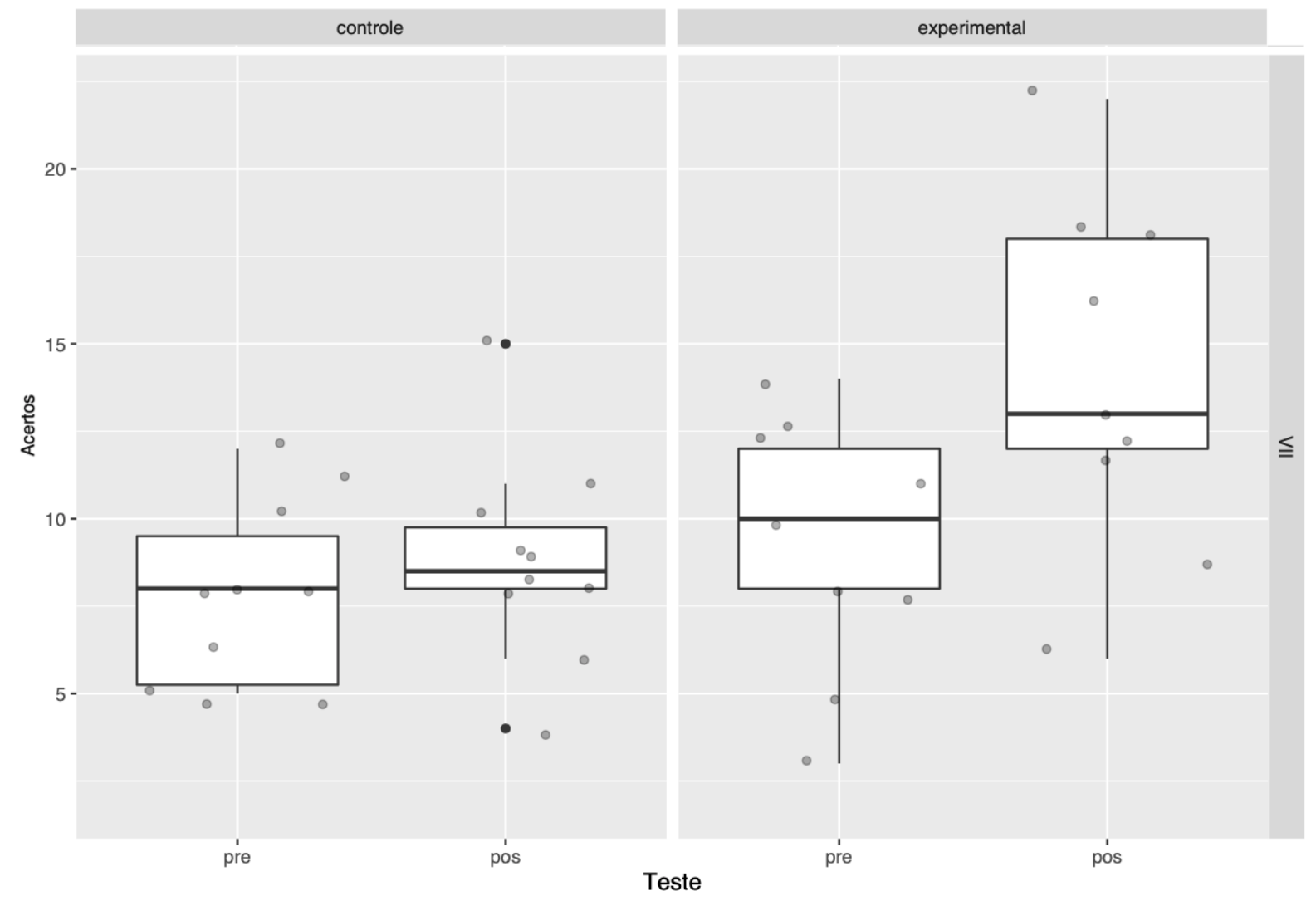

Figura 2 - Gráficos de caixa do pré- e pós-teste do grupo controle (esquerda) e grupo experimental (direita) do semestre VII.

Fonte: elaborado pelos autores.

Diferentemente do que aconteceu no grupo experimental, nem todos os participantes do grupo controle apresentaram um aumento no número de acertos entre o pré- e o pós-teste. Por exemplo, o participante SVII PC1 decaiu seu número de acerto de 11 para 6 (dado um nota de (2,31); o mesmo pode ser dito sobre o participante SVII PC9, que teve um total inicial de 5 acertos (nota 1,92) e decaiu para 4 acertos (nota 1,54). Observamos que os participantes SVII PC3 e SVII PC10 não demonstraram nenhum tipo de evolução em suas notas $(3,08)$ e no número de acertos (total de 8 acertos).

Tal resultado, quando colocado em comparação com o grupo experimental, observa o quão válido foi o período de instrução, que, apesar de curto, foi capaz de trazer benefícios também para os grupos mais avançados de inglês como LE. Desse modo, mostra-se válido todo e qualquer tempo gasto utilizado no ensino desses aspectos.

Os resultados apresentados convergem para a premissa exposta na introdução, de que o conhecimento explícito, neste caso sobre os fenômenos de sândi em língua inglesa, pode contribuir com o desenvolvimento de uma L2, uma vez que ele pode se tornar conhecimento implícito (ALVES, 2004; DEKEYSER, 1995; R. ELLIS, 2001; LIMA JR, 2010). Os resultados também revelam que o sistema linguístico da L1 de aprendizes interage com o sistema em desenvolvimento da L2, uma vez que a percepção dos alunos, dos dois grupos, sofre influências do sistema sonoro da L1, plenamente desenvolvido (FLEGE, 2003; PEROZZO, 2013). 


\section{CONCLUSÃO}

O presente estudo teve como objetivo pesquisar o efeito da instrução explícita de sândis na percepção auditiva de aprendizes brasileiros de inglês como língua estrangeira. O objetivo foi plenamente alcançado ao investigar o desempenho em um teste de percepção auditivo de alunos brasileiros de semestre II e de semestre VII de inglês, tanto em um grupo controle como em um grupo experimental, este último tendo recebido 4 aulas (intervenções) de 20 minutos cada de instrução explícita sobre fenômenos de sândi externo em inglês.

A questão de pesquisa norteadora foi: qual é a influência do ensino explícito de aspectos suprassegmentais, no caso os sândis, da língua inglesa ao ser usado como um instrumento na aprendizagem perceptual da língua falada? Consideramos como hipótese básica que o ensino explícito de aspectos suprassegmentais, os sândis, dentro da sala de aula de inglês como LE promoveria uma melhor percepção auditiva nos alunos. A resposta para a pergunta é a de que o ensino explícito dos sândis permitiu aos alunos, tanto de semestre II como de semestre VII, uma melhor percepção auditiva, pois lhes apresentou aspectos mais específicos de pronúncia em contextos suprassegmentais. Os aprendizes internalizam, por intermédio da metalinguagem, o fato de que palavras podem perder sons, serem geminadas, modificadas, colocadas juntas e, pela prática guiada, podem ficar mais bem preparados para percebê-las auditivamente. A hipótese foi, então, confirmada, tanto qualitativamente, ao se olhar para os dados individuais de pré- e pós-teste dos alunos dos grupos controle e experimental de cada semestre, como também quantitativamente, por meio de testes de Wilcoxon pareados.

Apesar das poucas intervenções e de um tempo relativamente curto em que a instrução explícita dos sândis ocorreu para esta pesquisa, podemos observar o resultado positivo aqui conseguido. Com essa pesquisa, pregamos a importância de os professores, pesquisadores e aprendizes se dedicarem ao estudo e ao ensino desses aspectos de pronúncia, os sândis, para uma melhor percepção auditiva dos aprendizes. Há limitações nesta pesquisa, sendo a principal a necessidade de verificar a habilidade de percepção auditiva desses alunos no longo prazo, a fim de verificar a retenção dos efeitos do ensino explícito. De qualquer maneira, esta pesquisa tem contribuições tanto para área de ensino da pronúncia como também para a área de pesquisa em desenvolvimento fonológico de línguas estrangeiras.

\section{REFERÊNCIAS}

ALVES, U. K. O papel da instrução explícita na aquisição fonológica do inglês como L2: evidências fornecidas pela teoria da otimidade. Dissertação (Mestrado em Linguística Aplicada). Escola de Educação, Universidade Católica de Pelotas, Pelotas, 2004.

BISOL, L. Sândi externo: O processo e a variação. In.: M. Kato (org.). Gramática do Português falado. Editora Unicamp, 2000. pp.55-96.

BYBEE, JOAN. 2001. Phonology and Language Use. Cambridge: Cambridge University Press

CELCE-MURCIA, M., BRINTON, D.M.; GOODWIN, J.M. Teaching pronunciation: A Reference for Teachers of English to Speakers of Other Languages. Cambridge: Cambridge University Press, 1996.

DEKEYSER, R. The Robustness of Critical Period Effects in Second Language acquisition. Studies in Second Language Acquisition, 22, 1995, p. 499-534.

ELLIS, N. C. Usage-based and form-focused language acquisition: the associative learning of 
constructions, learned attention, and the limited L2 endstate. In: ROBINSON, P.; ELLIS, N. C. (Eds.). . Handbook of cognitive linguistics and second language acquisition. New York: Routledge, 2008. p. 90-125.

ELLIS, R. Form-focused instruction and second language learning. Oxford: Oxford University Press, 2001.

ELLIS, R. Explicit form-focused instruction and second language acquisition. In: SPOLSKY, B.; HULT, F. M. (Eds.). . The handbook of educational linguistics. Oxford, Massachusetts, Victoria: Blackwell Publishing, 2008. p. 437-455.

FLEGE, J. Second language speech learning theory, findings, and problems. In: STRANGE, W. (Org.) Speech perception and linguistic experience: issues in cross-language research. Baltimore: York Press, 1995. p. 233-277.

FLEGE, J. E. Assessing constraints on second-language segmental production and perception. In: MAYER, A.; SCHILLER, N. (Eds) Phonetics and Phonology in Language Comprehension and Production, Differences and Similarities. Berlin: Mounton de Gruyter, 2003. pp 319-355.

JOHNSON, M. A Philosophy of Second Language Acquisition. Londres: Yale University Press, 2004.

LEATHER, J. Phonological acquisition in multilingualism. In: GARCÍA MAYO, M. P.; GARCÍA LECUMBERRI, M. L. Age and the acquisition of English as a foreign language. Clevedon, Tonawanda NY e Ontário: Multilingual Matters Ltd, 2003. Cap. 2, p. 23-58.

LIMA JR, R. M. Uma investigação dos efeitos do ensino explícito da pronúncia na aula de inglês como língua estrangeira. Revista Brasileira de Linguística Aplicada, Belo Horizonte, v. 10, n. 3, p. 747-771, 2010. Disponível em:

<http://www.scielo.br/scielo.php?script=sci_arttext\&pid =S1984-

63982010000300013\&lng=en\&nrm=iso >. Acesso em: 17 Mar. 2017.

PEROZZO, Reiner Vinicius. Percepção de oclusivas não vozeadas sem soltura audível em codas finais do inglês (L2) por brasileiros: o papel do contexto fonético-fonológico, da instrução explícita e do nível de proficiência. Dissertação - (Mestrado em Linguística) Programa de Pós-Graduação em Letras da Universidade Federal do Rio Grande do Sul, 2013.

PERUCCI, MARGARETH. The effect of sandhi-forms on L2 listening comprehension tasks. (Mestrado em Linguística Aplicada e Língua Inglesa) Programa de Pós-Graduação em Letras/Inglês e Literatura Correspondente, Universidade Federal de Santa Catarina, 2005.

SCHMIDT, Richard. The role of consciousness in second language learning. Applied Linguistics 11, 1990, p. 129-158.

SILVEIRA, R.; ALVES, U. Noticing e Instrução Explícita: aprendizagem fonético-fonológica do morfema. Ed. Universidade Federal de Santa Catarina, 2009.

Submetido em 22/10/2019

Aceito em 03/01/2020

Publicado em 30/04/2020 